\title{
Nitrogênio e Carbono espaço-temporais dissolvidos na precipitação e lixiviado da serrapilheira em duas microbacias Amazônicas
}

O estudo objetiva avaliar a dinâmica de nitrogênio e carbono dissolvidos em lixiviado da serrapilheira e precipitação, nas microbacias do Cumaru e São João (cerca de $12 \mathrm{~km}$ do município de Igarapé-Açu, no nordeste paraense), sob 4 diferentes manejos para cada microbacia: vegetação ripária, capoeira, sistema agroflorestal (SAF) e sistema de corte e trituração. As amostras foram coletadas mensalmente de fevereiro de 2014 a abril de 2015. O lixiviado da serrapilheira foi obtido pela solução escoada sob a camada de serrapilheira no solo em quadrantes de 1×1 m, enquanto que a precipitação se coletou por calhas conectadas a galões, sendo verificado in loco os parâmetros físico-químicos e analisado em laboratório, após adição de preservantes e filtragem: Carbono Orgânico Dissolvido (COD), Carbono Inorgânico Dissolvido (CID), Nitrogênio Orgânico Dissolvido (NOD), amônio (NH4+) e nitrato (NO3-). Onde verificou-se interferência dos períodos de transição climatológica sob a disponibilidade de nutrientes e os parâmetros físico-químicos avaliados; sendo as épocas mais chuvosas responsáveis por altas na acidez, na lixiviação e no consumo de oxigênio, já as menos chuvosas apresentaram elevação nos teores dos nutrientes analisados (especialmente em sistemas naturais e mais diversificados), exceto os ânions nitrogenados. Os SAFs e sistemas corte e trituração (menor proporção) atuaram significativamente no aproveitamento dos nutrientes lixiviados sob o solo

Palavras-chave: Diferentes manejos; Transição climatológica; Nutrientes; Sistema agroflorestal; Sistema de corte e trituração.

\section{Dissolved space-time Nitrogen and Carbon in precipitation and litter leachate in two small Amazonian watersheds}

\begin{abstract}
The study aims to evaluate the dynamics of dissolved nitrogen and carbon in litter leachate and precipitation in small watersheds at Cumaru and São João (about $12 \mathrm{~km}$ of the municipality of Igarapé Açú, in northeaStern Paraense), under different managements to each small watershed: riparian vegetation, secundary vegetation, agroforest system (AFS) and cut and grind system. The samples wewrw colleted montly from february 2014 to april 2015 . The litter leachate was obtained by the solution drained under the litter layer in quadrants of $1 \times 1 \mathrm{~m}$, while the precipitation was collected by gutters connected to gallons, being checked in loco the physical-chemical parameters and analyzed in the laboratory, after addition of preservatives and filtering: Dissolved Organic Carbon (DOC), Dissolved Inorganic Carbon (DIC), Dissolved Organic Nitrogen (DON), ammonium (NH4+) and nitrate (NO3-). It was found that the periods of climatological transition interfere at vailability of nutrientes and in physic-chemical parameters evaluated; being the rainiest seasons responsible for high acidity, leaching and oxygen consumption, while the less rainy periods showed elevation in the contents of the analyzed nutrients (especially in natural and more diversified systems), except nitrogen anions. AFSs and cut and grind systems (lesser proportion) acted in the use of leachate nutrients under the soil.
\end{abstract}

Keywords: Different managements; Climatological transition; Nutrients; Agroforestry system; Cut and grind system.

Topic: Desenvolvimento, Sustentabilidade e Meio Ambiente

Reviewed anonymously in the process of blind peer.
Received: 04/12/2020

Approved: 21/12/2020
Leonardo Lemos Almeida (iD)

Universidade Federal do Pará, Brasil

http://lattes.cnpq.br/7161047555856781

http://orcid.org/0000-0002-5124-8757

leolemos202@gmail.com

Lady Laura Pantoja Pereira de Carvalho (iD

Universidade Federal do Pará, Brasil

http://lattes.cnpq.br/2028736708031465

http://orcid.org/0000-0002-0886-2217

ladylauracarvalho78@gmail.com

Patricia Silva dos Santos

Faculdade Estácio de Belém, Brasil

http://lattes.cnpq.br/9543390291880232

http://orcid.org/0000-0001-7564-7376

ssilva.patriciasantos@gmail.com

6

DOI: 10.6008/CBPC2179-6858.2020.007.0047

\author{
Juliana Feitosa Felizzola (iD \\ Embrapa Amazônia Oriental, Brasil \\ http://lattes.cnpq.br/5328799930481659 \\ http://orcid.org/0000-0002-3932-0269 \\ julianafelizzola@gmail.com \\ Nilza Araujo Pacheco (iD) \\ Embrapa Amazônia Oriental, Brasil \\ http://lattes.cnpq.br/2377129321735194 \\ http://orcid.org/0000-0001-9012-9227 \\ nilza.pacheco@embrapa.br
}

Referencing this:

ALMEIDA, L. L.; CARVALHO, L. L. P. P.; SANTOS, P. S.; FELIZZOLA, J. F.; PACHECO, N. A.. Nitrogênio e Carbono espaço-temporais dissolvidos na precipitação e lixiviado da serrapilheira em duas microbacias Amazônicas. Revista Ibero Americana de Ciências Ambientais, v.11, n.7, p.602-618, 2020. DOI: http://doi.org/10.6008/CBPC21796858.2020 .007 .0047 


\section{INTRODUÇÃO}

A agricultura familiar na região da Amazônia, mas especificamente no Nordeste Paraense, é caracterizada pelos processos de derruba e queima para plantios de milho, feijão-Caupi e mandioca, além de outros cultivos, como o de maracujá e pimenta-do-reino. O manejo de derruba e queima no solo para plantios posteriores tem sido responsável por grandes perdas de nutrientes orgânicos e inorgânicos via processos de lixiviação e escoamento subterrâneo (REGO et al., 2017).

Recentemente, processos de manejos alternativos como a implantação de capoeiras por alguns anos, a técnica de corte e trituração (plantio direto na capoeira após trituração da vegetação) e a inserção de sistemas agroflorestais (combinação de espécies arbóreas e culturas agrícolas) como modo de subsistência, são considerados métodos que minimizam perdas de nutrientes via solo (SHIMIZU et al., 2014; REGO et al., 2017). Na área de estudo a vegetação ripária, que ocupa os setores marginais aos cursos d'água nas microbacias, vem sendo explorada nos processos de expansão dos pontos de cultivo. Estas diferentes coberturas de terra afetam a quantidade e qualidade de água e nutrientes que percolam no solo através da biomassa de cada sistema utilizado.

Nesta região, a dinâmica do processo de precipitação e escoamento superficial foi estudada por Wickel et al. (2001), que demonstrou que este deflúvio consiste inteiramente da saturação do fluxo superficial gerado na área alagada da floresta ripária, havendo saída de nutrientes pelo dossel da floresta no início do período chuvoso, diminuindo com a progressão desta estação. As perdas de nutrientes para as águas subterrâneas são significantes, segundo o mesmo autor. Mosaicos de vegetação, florestas ripárias e áreas alagadas são conhecidas pelos seus efeitos reguladores na quantidade e qualidade de água, recarregando aquíferos e reservas. Relações entre a presença de vegetação e os fluxos dos rios foram quantificadas e demonstrado que o volume da água dos rios mantém-se constante, devido ao fator regulador de plantas na quantidade de água escoada (LIKENS et al., 1990).

Desta forma, o lixiviado da serrapilheira (denominação dada à precipitação que atravessa a camada de serrapilheira e que posteriormente irá adentrar o solo) juntamente com a precipitação, destacam-se como vias importantes de entrada de substâncias no sistema solo-planta (MIRANDA et al., 2018; CRUZ et al., 2018). Neste contexto, a folhas presentes nessa camada tem relevante papel, visto que a mistura de diversas espécies aumenta a atividade microbiana e/ou sua abundância no solo e, consequentemente, a decomposição da serrapilheira pelo mesmo. Logo, a diversidade de espécies de folhas ocasiona diferentes porcentagens de liberação de nutrientes (SILVEIRA et al., 2011).

O fluxo nutricional de um ecossistema normalmente tem sua limitação associada à quantidade de nitrogênio $(\mathrm{N})$, que constitui alguns componentes das células vegetais e é necessário em grandes concentrações às plantas. $\mathrm{O} N$ está no solo majoritariamente na forma orgânica ( $98 \%$ do $\mathrm{N}$ total), a outra parte vem da mineralização desta fração orgânica pela decomposição de microrganismos, resultando em amônio $\left(\mathrm{NH}_{4}{ }^{+}\right)$, nitrato $\left(\mathrm{NO}_{3}^{-}\right)$e, em certos casos, pequenas quantidades de nitrito $\left(\mathrm{NO}_{2}^{-}\right)$- formas inorgânicas de $\mathrm{N}$ e assimiláveis pela vegetação (FIGUEIREDO, 2016). 
Outro macronutriente essencial é o carbono (C), principal constituinte da matéria orgânica cuja maior parte está na forma de carbono orgânico dissolvido (COD). O COD origina-se principalmente na decomposição de plantas e animais, tal como no produto de excreção destes organismos (SILVA et al., 2007). A porção inorgânica deste macronutriente é encontrada especialmente como carbono inorgânico dissolvido (CID), ocorrendo em três frações: $\mathrm{CO}_{2}$ livre $\left(\mathrm{CO}_{2}+\mathrm{H}_{2} \mathrm{CO}_{3}\right)$, íons bicarbonato $\left(\mathrm{HCO}_{3}{ }^{-}\right)$e carbonato $\left(\mathrm{CO}_{3}{ }^{2-}\right)$ (SOUSA, 2007).

O manejo do solo (as diferentes condições ambientais às quais as vegetações estão inclusas), os parâmetros físico-químicos, bem como as estações ou temporadas que alteram o clima local, interferem de diversos modos na produção de serrapilheira, e no fluxo de N e C (OLIVEIRA et al., 2017; CARVALHO et al., 2019). Aliado a isto, as relações C:N podem revelar a qualidade da matéria orgânica, tendo relação com a facilitação do processo de mineralização (TROEH et al., 2007).

Neste estudo, propomos mostrar a quantidade de nutrientes que interagem com a biomassa da serrapilheira formando uma solução devido ao contato com a água da chuva, com a hipótese de que grande parte dos nutrientes químicos do solo provém desta interação e não somente devido as origens geomorfológicas do solo. O fluxo de água e nutrientes nas interfaces vegetação/solo/água superficial/água subterrânea é vital para a manutenção sustentável dos ecossistemas naturais (TUNDISI et al., 2008; SOMMER et al., 2004).

Portanto, neste trabalho objetivou-se verificar a variação espaço-temporal de nitrogênio e de carbono dissolvidos no lixiviado da serrapilheira e na precipitação, sob diferentes manejos (vegetação ripária, capoeira, sistema agroflorestal e cultivo preparado sob corte e trituração) em duas microbacias hidrográficas localizadas no nordeste paraense (Cumaru e São João).

\section{METODOLOGIA}

\section{Área de Estudo}

A área de estudo (Figura 1) compreende as microbacias dos igarapés Cumaru (MIC, 4135 ha; $1^{\circ} 11^{\prime} \mathrm{S}$, $47^{\circ} 34^{\prime} \mathrm{W}$ ) e São João (MISJ, 2654 ha; $01^{\circ} 10^{\prime} \mathrm{S}, 47^{\circ} 32^{\prime} \mathrm{W}$ ), pertencentes a bacia do rio Maracanã, situadas a cerca de $12 \mathrm{~km}$ do município de Igarapé-Açu, no nordeste paraense. A mesma possui clima caracterizado predominantemente como do tipo Ami e subtipo Am2 conforme a escala Köppen, com 26,5 ํ C como temperatura média anual, precipitação anual média em torno de $2.500 \mathrm{~mm}$ e umidade relativa do ar entre 80-85\%. A região possui solos do tipo Argissolo Amarelo Distrófico de textura arenosa a média, sendo ácidos, profundos e bem drenados (LIMA et al., 2007; SILVA et al., 2009; MENEZES, 2018).

Para cada uma das microbacias selecionou-se 4 regiões sob tratamentos distintos, sendo estas: Vegetação Ripária (Vr), Floresta Sucessional (Capoeira, Cp), Agricultura de corte e trituração (Tt) e Sistema agroflorestal (Saf), observados na Figura 1 e na Tabela 1. Onde as regiões Tt, $\mathrm{Cp}$ e $\mathrm{Vr}$ estão situadas no entorno das nascentes de suas respectivas microbacias (Menezes, 2018). A faixa de serrapilheira de cada um dos tipos de tratamentos aqui trabalhados está visível na Figura 2. 


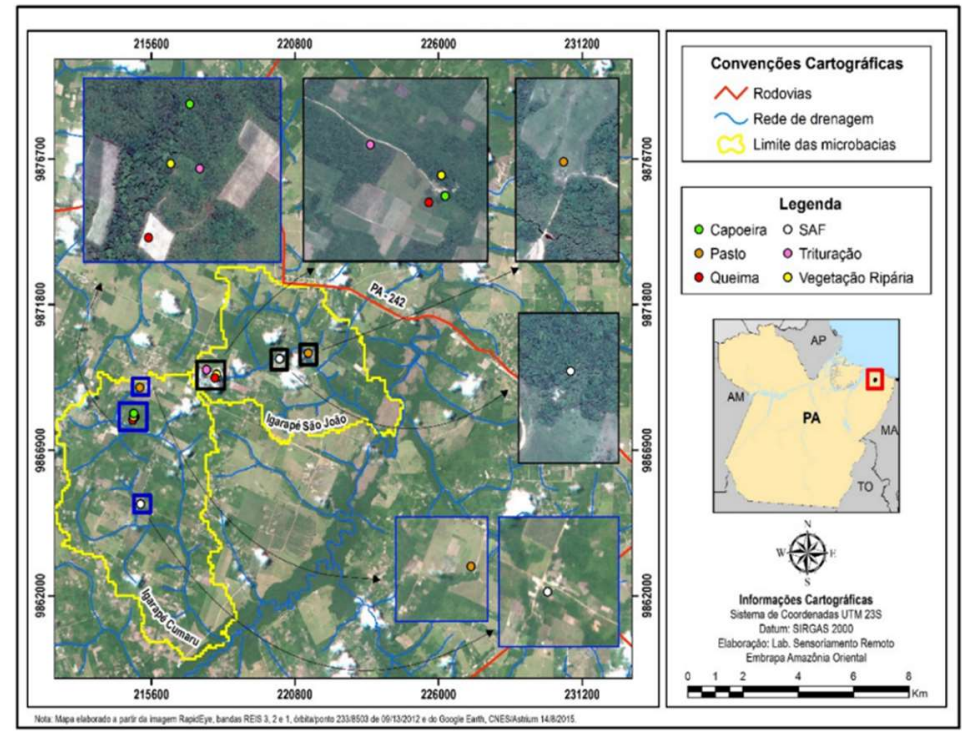

Figura 1: Área de estudo (Laboratório de Sensoriamento Remoto da Embrapa Amazônia Oriental, 2015).

Tabela 1: Tratamentos por área de estudo.

\begin{tabular}{|c|c|c|c|c|}
\hline Microbacia & Tratamento & Especificações & Latitude & Longitude \\
\hline \multirow[t]{4}{*}{ MIC } & $\mathrm{Cp}$ & Ecossistema de floresta sucessional ( $<20$ anos). & $47^{\circ} 33^{\prime} 40,48^{\prime \prime} \mathrm{W}$ & $1^{\circ} 11^{\prime} 30,64^{\prime \prime} \mathrm{S}$ \\
\hline & Tt & $\begin{array}{l}\text { Plantio de roça de mandioca (Manihot esculenta) manejado sem } \\
\text { queima, sob corte e trituração. }\end{array}$ & $47^{\circ} 33^{\prime} 39,88^{\prime \prime} \mathrm{W}$ & $1^{\circ} 11^{\prime} 34,59^{\prime \prime} \mathrm{S}$ \\
\hline & Saf & $\begin{array}{l}\text { Sistema agroflorestal estruturado com açaizeiros (Euterpe } \\
\text { olerácea Mart.), seringueiras (Hevea brasiliensis) e cupuaçuzeiros } \\
\text { (Theobroma grandiflorum). }\end{array}$ & $47^{\circ} 33^{\prime} 32,09^{\prime \prime} \mathrm{W}$ & $1^{\circ} 13^{\prime} 10,03^{\prime \prime S}$ \\
\hline & $\mathrm{Vr}$ & Floresta natural marginal ao igarapé Cumaru. & $47^{\circ} 33^{\prime} 40,73^{\prime \prime} \mathrm{W}$ & $1^{\circ} 11^{\prime} 34,53^{\prime \prime} \mathrm{S}$ \\
\hline \multirow[t]{4}{*}{ MISJ } & Cp & Ecossistema de floresta sucessional ( $<20$ anos). & $47^{\circ} 32^{\prime} 2,64^{\prime \prime} \mathrm{W}$ & $1^{\circ} 10^{\prime} 50,85^{\prime \prime} \mathrm{S}$ \\
\hline & Tt & $\begin{array}{l}\text { Plantio de roça de mandioca (Manihot esculenta) manejado sem } \\
\text { queima, sob corte e trituração. }\end{array}$ & $47^{\circ} 32^{\prime} 26,08^{\prime \prime} \mathrm{W}$ & $1^{\circ} 10^{\prime} 35,49^{\prime \prime} \mathrm{S}$ \\
\hline & Saf & $\begin{array}{l}\text { Sistema agroflorestal estruturado com cupuaçuzeiros (Theobroma } \\
\text { grandiflorum) e pimenta (Piper nigrum). }\end{array}$ & $47^{\circ} 30^{\prime} 49,76^{\prime \prime} \mathrm{W}$ & $1^{\circ} 10^{\prime} 31,50^{\prime \prime} \mathrm{S}$ \\
\hline & $\mathrm{Vr}$ & Floresta natural marginal ao igarapé São João. & $47^{\circ} 32^{\prime} 3,74^{\prime \prime} \mathrm{W}$ & $1^{\circ} 10^{\prime} 25,25^{\prime \prime} \mathrm{S}$ \\
\hline
\end{tabular}

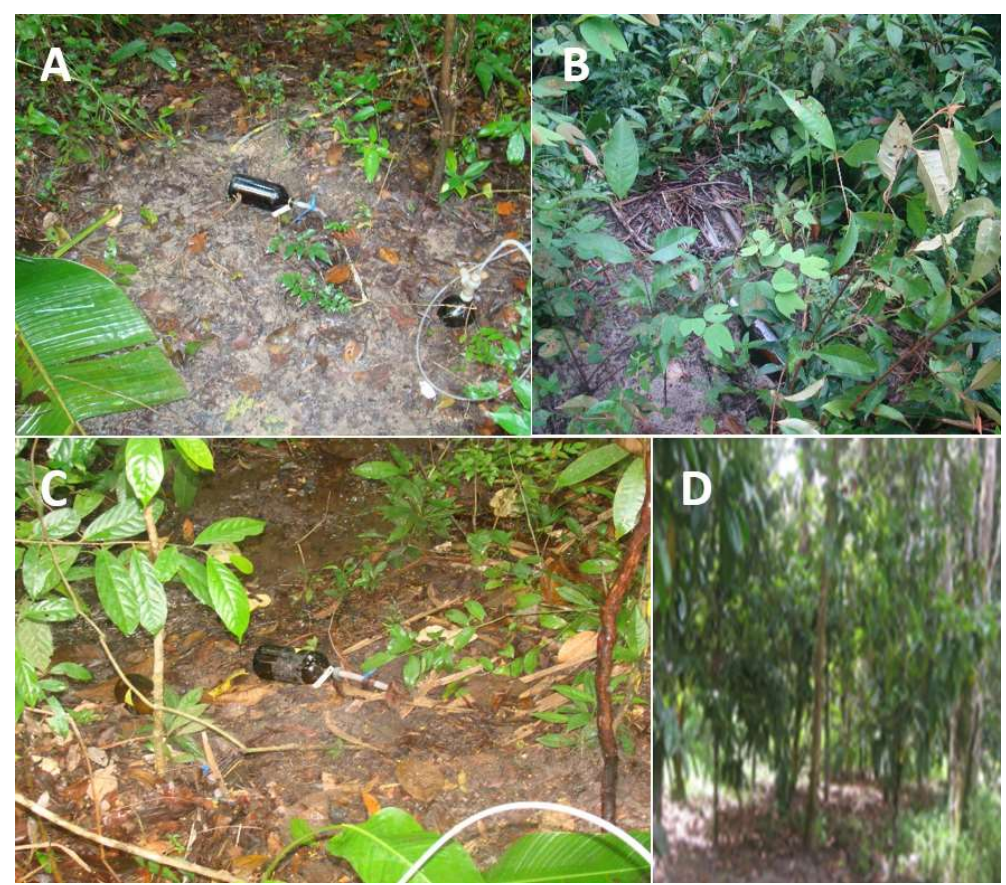

Figura 2: Faixa de serrapilheira dos tratamentos das áreas de estudo (A: Vegetação Ripária da MIC; B: Sistema de corte e trituração da MIC; C: Capoeira da MIC e D: Sistema Agroflorestal da MISJ). 


\section{Coletores, amostragem e análises}

Coletaram-se amostras de lixiviado da serrapilheira nas 4 regiões de tratamento de cada microbacia. Estas foram obtidas por meio de coletores de $1 \times 1 \mathrm{~m}$, dispostos em forma de quadrante, e demarcados por 3 peças de madeira e uma calha de PVC no lado de menor declividade, sendo drenada a um frasco coletor de vidro de cor âmbar de $1 \mathrm{~L}$ sob o solo (com abertura coberta por tela polimérica no intuito de impedir a entrada de insetos e material da serrapilheira). Utilizaram-se de 6 a 7 repetições por tratamento. Para este tipo de amostra foi realizada medição de seu volume em proveta de plástico, sendo a razão entre o volume lixiviado (em Litros) pela área do coletor, delimitado pelo quadrante (equivalente a $1 \mathrm{~m}^{2}$ ), utilizada para a determinação da medida de Solução Lixiviada pela Serrapilheira (SALS, em mm).

Foram coletadas, ainda, amostras de precipitação em cada microbacia, porém em locais externos às 4 regiões de tratamento. Para tanto, usaram-se calhas de PVC (a altura de 2 metros, em relação ao solo) conectadas a galões coletores de $5 \mathrm{~L}$, também com telas alocadas nas aberturas dos recipientes. Além disso, foram utilizados dados de precipitações oriundos da estação meteorológica convencional da Embrapa Amazônia Oriental no município de Igarapé-Açu $\left(47^{\circ} 35^{\prime} \mathrm{W}, 01^{\circ} 11^{\prime} \mathrm{S}\right)$. Ambas as amostragens ocorreram entre o período de fevereiro de 2014 a abril de 2015, sob regime mensal.

Para o lixiviado da serrapilheira, as amostras foram divididas em três porções, sendo a primeira submetida a verificação da temperatura, pH, condutividade elétrica (CE) e Saturação de Oxigênio Dissolvido (\%OD) em sonda multiparâmetro (modelo U-52 da HORIBA). As outras duas foram encaminhadas para análise de nutrientes juntamente com a precipitação.

Já para a precipitação, as amostras se dividiram em duas porções que, com as duas restantes do lixiviado da serrapilheira, foram armazenadas em frascos de polietileno de $250 \mathrm{~mL}$ e seguiram para análise de nutrientes da seguinte forma: uma das porções foi reservada com solução de ácido fosfórico $\left(\mathrm{H}_{3} \mathrm{PO}_{4}\right)$ a 10\% como preservante, para posterior quantificação de Carbono Orgânico Dissolvido (COD) e Nitrogênio Orgânico Dissolvido (NOD); bem como a outra, com Thymol como preservante, para subsequente quantificação de Carbono Inorgânico Dissolvido (CID), Amônio $\left(\mathrm{NH}_{4}^{+}\right)$e Nitrato $\left(\mathrm{NO}_{3}{ }^{-}\right)$. Estas foram encaminhadas ao Laboratório de Análises de Sistemas Sustentáveis (LASS) da Embrapa Amazônia Oriental,

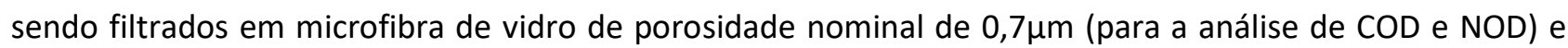
microfibra de acetato de celulose de porosidade $0,45 \mu \mathrm{m}$ (para análise de CID e a iônica) e armazenados em câmara escura sob $4^{\circ} \mathrm{C}$ até análise.

Foram determinados em Analisador de Carbono Orgânico Total (TOC V-CSN da Shimadzu, com módulo TNM-1 acoplado para a análise de Nitrogênio), através da combustão catalítica a $720^{\circ} \mathrm{C}$ seguida pela detecção e quantificação em infravermelho não dispersivo, os teores de COD, CID e NOD. Enquanto que em Cromatógrafo de Íons (Dionex DX-120, com Software Chromeleon utilizado como ferramenta de automação) foram mensuradas as concentrações dos íons nitrogenados (amônio e nitrato). 


\section{Análise Estatística}

Os dados obtidos foram submetidos aos testes de normalidade de Ryan Joiner (similar ao de ShapiroWilk) e Kolmogorov-Smirnov, com $(p<0,01)$ para ambos. Após isto, foi executada a análise descritiva dos resultados e a de variância por ANOVA, além do teste de significância de Tukey a $5 \%(p<0,05$ e $p<0,01)$ e da análise entre as variáveis estudadas por meio do teste de correlação de Spearman $(p<0,05$ e $p<0,01)$. As médias com valores $(p>0,05)$ foram consideradas como sem distinção significativa entre os tratamentos. Foram utilizados os softwares Excel (da Microsoft) e Minitab 17 para análise dos resultados.

\section{RESULTADOS E DISCUSSÃO}

Regime pluviométrico e parâmetros físico-químicos em lixiviado da serrapilheira ao longo dos períodos climáticos observados

A região apresentou os maiores valores de precipitação atmosférica entre os meses de fevereiro e junho de 2014 (com o pico ocorrido em abril), e entre março e abril de 2015 (Figura 3); estes valores foram superiores à média mensal estipulada (em torno de $208 \mathrm{~mm}$ ) referente a precipitação anual observada por Rosa (2007) e Menezes (2018) em pesquisa na mesma área. Contudo, o período do estudo apresentou uma diminuição no volume de chuvas em relação aos anos anteriores (Figura 3), sendo esta diminuição relacionada, possivelmente, a ocorrência do fenômeno El niño que aconteceu em 2014 e se estendeu até meados de 2016, o qual é caracterizado pela redução das chuvas nas porções leste e norte da Floresta Amazônica, ocasionando algumas estiagens cíclicas na região.

Para efeito de avaliação deste trabalho, considerou-se os meses de julho e agosto de 2014 (pluviosidade em torno de $100 \mathrm{~mm}$ ) como período de transição chuvoso-estiagem (Tr1), porque são antecessores aos meses de menor pluviosidade (abaixo de $50 \mathrm{~mm}$ ); semelhantemente, os meses de fevereiro de 2014, janeiro de 2015 e fevereiro de 2015 (tidos como o último mês do período de menor intensidade de chuvas e o primeiro do aumento dessas, em ordem cronológica) foram tratados como período de transição estiagem-chuvoso (Tr2). Assim, os meses de março a junho de 2014 e de março a abril de 2015 compreendem as estações chuvosas (Ch), ao passo que os meses de setembro a dezembro de 2014 correspondem ao período seco ou de estiagem (Es).

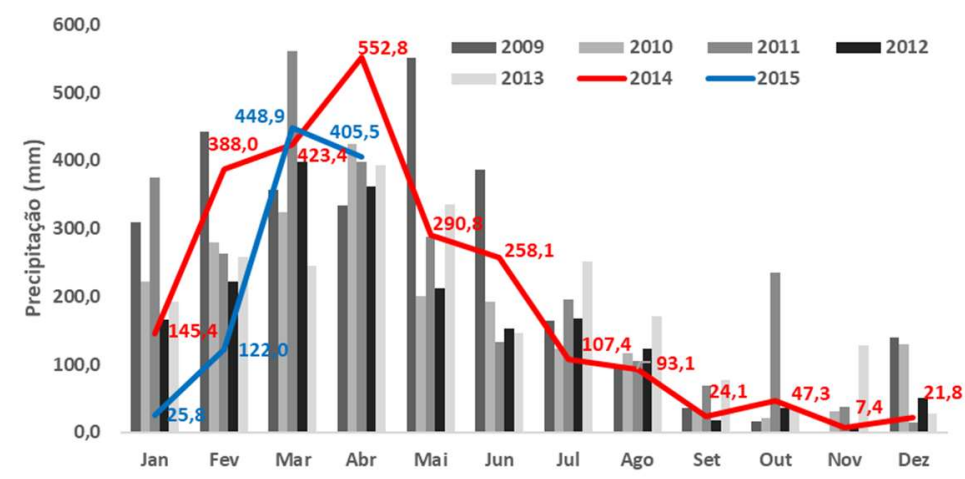

Figura 3: Precipitação atmosférica mensurada ao longo do período de estudo. Fonte: adaptado de Menezes (2018). 
De igual maneira, no lixiviado da serrapilheira, as medidas de solução acumulada (SALS), contidas na Figura 4, apresentaram-se maiores nos períodos chuvosos de 2014 e 2015 na maioria dos tratamentos estudados, à exceção do tratamento $\mathrm{Vr}$, que permaneceu, em geral, acima de todos os demais e que também manteve um perfil crescente, na MIC, entre os meses de julho e setembro de 2014 (onde a precipitação atmosférica expressou perfil decrescente, como observado na Figura 3). Os baixos valores de SALS durante o período de menor precipitação foram responsáveis pela não mensuração destas amostras durante estes meses, sendo reservado, quando possível, para as análises químicas.

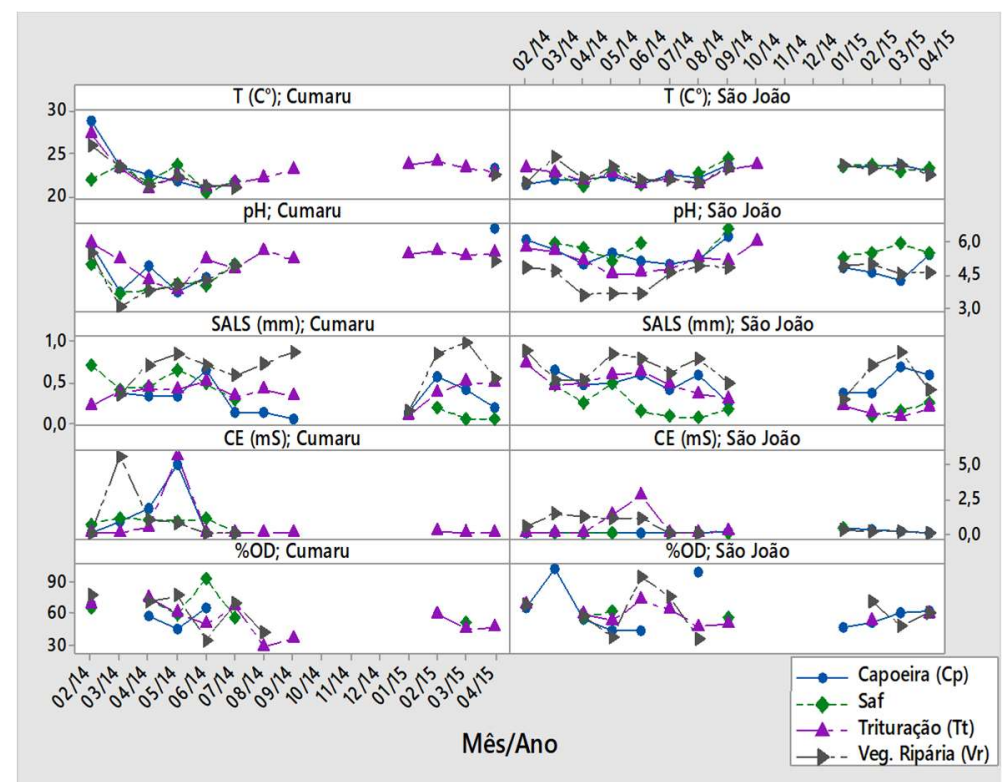

Figura 4: Parâmetros físico-químicos no lixiviado da serrapilheira ao longo do período de estudo.

Para os parâmetros físico-químicos, analisados no lixiviado da serrapilheira (Figura 4), observa-se uma redução no pH e, consequentemente, o aumento do caráter ácido (com destaque para os tratamentos Tt e Vr na MISJ no ano de 2014), acompanhado pela redução da temperatura durante o período de maior intensidade de chuvas (Figura 3), sendo obtido, após a análise de correlação entre ambos, o coeficiente de valor $\sigma=0,155$ (a nível de significância de $p<0,05$ ). Segundo Rosa (2007), este fenômeno remete-se ao aumento da lixiviação ocorrida na superfície que pode atuar carreando ácidos orgânicos em maior intensidade até o leito de rios, fato este que explica os reduzidos valores encontrados na Vr.

Os valores de CE mantiveram-se abaixo de $2 \mathrm{mS}$, com a ocorrência de poucas alterações ao longo dos meses de pesquisa, a exceção, na MIC dos meses de março de 2014 ( $V r$, com 5,68 $\pm 8,75$ mS) e maio de 2014

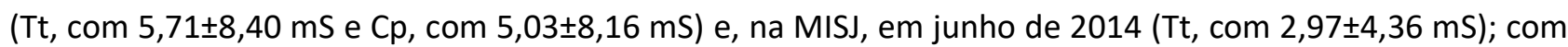
variação entre as repetições e ambos estes entre os períodos Ch e Tr1.

Os dados de porcentagem de oxigênio dissolvido (\%OD), apresentados na Figura 4, revelam uma flutuação em seus resultados durante todo o período de estudo. Aqui é preciso considerar os diversos fatores que podem intervir nos valores de OD, já que sua concentração pode variar tanto sazonalmente quanto em períodos de 24 horas, por conta da temperatura e atividade biológica (DARWICH, 2005). Além disso, como as mensurações foram realizadas em lixiviado da serrapilheira, que se trata de um ambiente com pouco volume de água e próximo à superfície atmosférica, este tipo de amostra pode estar mais suscetível às 
interferências sobre a \%OD.

\section{Avaliação das concentrações das frações orgânicas e inorgânicas de carbono e nitrogênio por tipos de vegetação}

No que diz respeito aos teores de COD (Figura 5) obtidos, foi observado o aumento com a chegada do período de menor intensidade de chuvas, época evidenciada naturalmente por uma maior taxa de deposição de matéria orgânica (MAESTRI et al., 2019; BARREIROS, 2019), persistente até o início do período chuvoso subsequente, circunstância ocorrida em ambas as microbacias. Associado a isto, observa-se o fato do perfil da Tt se comportar acompanhando o da $\mathrm{Vr}$ e da $\mathrm{Cp}$ ao longo dos meses (em torno de $20 \mathrm{mg} / \mathrm{L}$, em ambas as microbacias) como uma boa resposta deste sistema produtivo. Segundo Rego et al. (2017), sistemas estilo corte e trituração atuam substancialmente na manutenção da umidade do solo e dos níveis de matéria orgânica de forma mais eficiente.

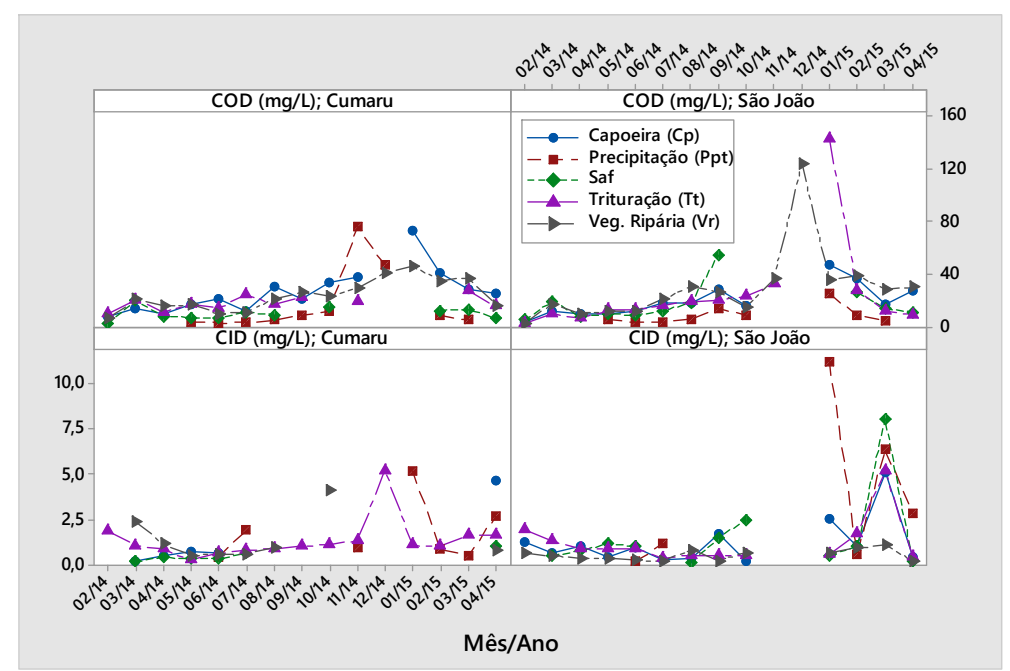

Figura 5: Teores de COD e CID obtidos ao longo do período de estudo.

O observado para o COD na Ppt manteve-se abaixo dos lixiviados ao longo do tempo nas duas áreas de estudo, a exceção de novembro de 2014 (sendo este o maior valor encontrado, seguido pelo lixiviado da Cp em janeiro de 2015) e dezembro de 2014 na MIC. De acordo com a Figura 3, estes 3 últimos meses citados (nov/14, dez/14 e jan/15) foram os de menores medidas de precipitação atmosférica, com 7,4 mm; 21,8 mm e $28,8 \mathrm{~mm}$; respectivamente. Para o COD do lixiviado da serrapilheira, os valores mínimos ocorreram ao fim do Tr2, em fevereiro de 2014, no Saf da MIC (1,65 mg/L) e na Tt da MISJ (1,91 mg/L) enquanto que os máximos se obtiveram ao início da Tr2, em janeiro de 2015, na Cp da MIC (72,70 mg/L) e na Tt da MISJ (141,75 $\pm 24,78$ $\mathrm{mg} / \mathrm{L})$.

Vale ressaltar que nos períodos mínimos citados foram obtidos, conforme a Figura 4, elevadas medidas de SALS $(0,72 \pm 0,25 \mathrm{~mm}$ no Saf da MIC e 0,74 mm na Tt da MISJ) e de saturação de oxigênio dissolvido

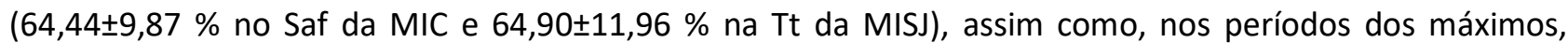
também citados anteriormente, reduzidas medidas de SALS (0,14 mm na Cp da MIC e 0,22 $\pm 0,16 \mathrm{~mm}$ na Tt da MISJ), cujos valores de \%OD não foram mensurados; sendo este fenômeno referente ao aumento dos processos respiratórios (ocasionando alta no consumo de oxigênio) gerado por maiores teores de COD. 
Semelhante a isto, para águas fluviais, Neill (2001) e Rosa (2007) também observaram o acréscimo do consumo de oxigênio ser intensificado pelo regime de cheias. No que se refere ao caso, a análise estatística constatou baixa correlação negativa $(\sigma=-0,280)$, porém significativa $(p<0,05)$ entre \%OD e SALS.

Ao se comparar com os obtidos para CID (Figura 5), percebe-se uma maior homogeneidade deste (com valores, em geral, abaixo de $5 \mathrm{mg} / \mathrm{L}$ ), a exceção do fim do período Es e início do período Ch em 2015, onde passou-se a apresentar maiores variações entre os tratamentos de estudo. Os valores máximos foram encontrados na Ppt $(5,20 \mathrm{mg} / \mathrm{L}$ na MIC e $11,18 \mathrm{mg} / \mathrm{L}$ na MISJ, ambos em janeiro de 2015, sendo este um dos meses de menor intensidade de chuvas mensurado, conforme a Figura 3). A respeito destes resultados, a análise de variância dos mesmos demonstrou distinções a níveis de significância $(p<0,05)$ apenas entre o fator tratamento. Rosa (2007) verificou que na água dos igarapés Cumaru e São João, considerados como os cursos de drenagem principal das microbacias em questão, a redução do regime de precipitação atuou positivamente no aumento das concentrações de CID, devido ao fenômeno da diluição de compostos inorgânicos carbonatados pela água da chuva ocorrido no período chuvoso. Este efeito foi verificado na análise estatística, onde a condutividade, relacionada a concentração total de substâncias iônicas dissolvidas em solução (ENCINAS, 2016), teve correlação negativa e significativa $(p<0,01)$ em relação a SALS $(\sigma=-0,295)$.

Nota-se ainda que, ao contrário do observado em COD, para o CID (nos meses onde foi realizada amostragem) houve o posicionamento da Ppt, em geral, acima dos lixiviados da serrapilheira dos referidos tratamentos. Situação que sugere uma contribuição de COD pela precipitação, assim como uma retenção de CID na faixa da serrapilheira.

Aos teores de NOD (Figura 6) observa-se, ao longo dos meses, a existência de poucas flutuações (a exceção da MISJ no período seco); fato este que, possivelmente, influenciou a ocorrência de igual comportamento para os resultados da razão COD/NOD (Figura 6), com sobressalto na precipitação da MIC em novembro de 2014, onde foram observados teores de COD acima de $70 \mathrm{mg} / \mathrm{L}$ e baixas concentrações de NOD (Figuras 5 e 6). As maiores médias mensais de NOD foram encontradas em lixiviado da serrapilheira na Cp da MIC ao fim do período de transição chuvoso-seco $(50,98 \pm 64,47 \mathrm{mg} / \mathrm{L})$ e no da $\mathrm{Vr}$ na MISJ ao fim do período seco $(160,2 \mathrm{mg} / \mathrm{L})$. Ambos estes caracterizados por possuírem ecossistemas mais diversificados e propensos ao retorno dos nutrientes, em geral, com a queda de material proveniente da parte aérea das plantas, seguido de sua decomposição sobre o solo (BARREIROS, 2019), além de outros processos.

A ordem observada (NOD $>\mathrm{NO}_{3}>\mathrm{NH}_{4}{ }^{+}$) apresenta-se de acordo com os processos do ciclo do Nitrogênio, onde a fração orgânica é transformada em amônio a partir de processos de mineralização, possibilitados pela atuação de microrganismos heterotróficos, seguido pela conversão a nitrato por meio da nitrificação (FIGUEIREDO, 2016), sendo estas frações disponibilizadas para processos metabólicos ou perdidas por lixiviação. Aliado a isto, no presente estudo foi constatada baixa correlação, no entanto significativa $(p<0,05)$, entre as espécies iônicas nitrogenadas analisadas $(\sigma=0,245)$.

As análises químicas constataram a pouca contribuição destes íons pela Ppt, sendo, para o cátion $\mathrm{NH}_{4}{ }^{+}$, quantificado apenas um evento com a presença do mesmo na MIC $(0,34 \mathrm{mg} / \mathrm{L}$, em julho de 2014 , no início do Tr1) e dois na MISJ (em torno de 0,08 mg/L, nos meses de julho e agosto de 2014 cada e, portanto, 
também no período Tr1). Para o ânion $\mathrm{NO}_{3}{ }^{-}$, na MIC foram quantificados em maior frequência (com, ao todo, cinco ocorrências), porém todos os eventos situaram-se entre junho de 2014 (final do período Ch) e novembro de 2014 (mês do período Es com menor precipitação, de acordo com a Figura 3), sendo o valor mensurado superior aos obtidos no lixiviado da serrapilheira apenas em junho de 2014 (3,49 mg/L); enquanto que na MISJ também foi observado apenas um evento, em julho de 2014 (0,41 mg/L), em igual período de intensidade de chuvas em relação ao cátion anteriormente citado.

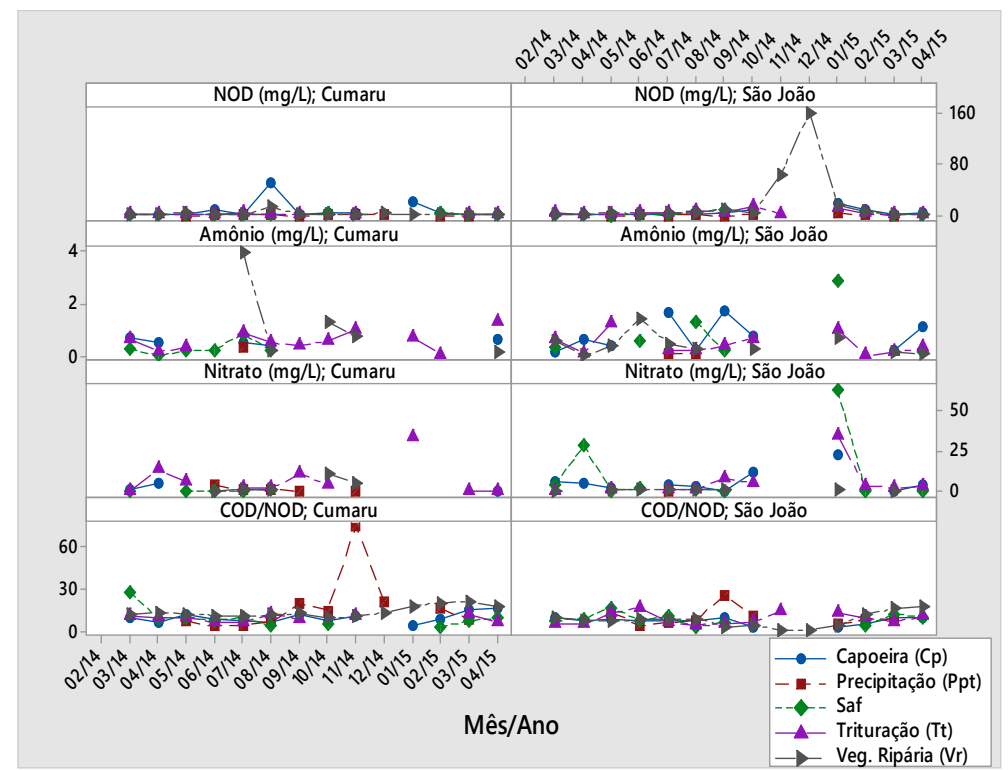

Figura 6: Teores de $\mathrm{NOD}, \mathrm{NH}_{4}{ }^{+}$e $\mathrm{NO}_{3}{ }^{-}$obtidos ao longo do período de estudo.

\section{Avaliação da dinâmica de nutrientes e atributos do lixiviado em função da matéria orgânica disposta sobre o solo}

Ao visualizarmos as médias gerais, contidas na Tabela 2, nota-se na MIC a presença de uma maior quantidade de COD e NOD (relacionados com a matéria orgânica) no lixiviado da Vr e Cp. Segundo Miranda et al. (2018), o transporte de matéria orgânica oriunda de faixas como o dossel e a serrapilheira influem positivamente na dinâmica do COD, sendo estas faixas mais complexificadas nestes dois tratamentos.

Em seguida, ainda para as concentrações de COD e NOD, no lixiviado da serrapilheira, temos a Tt acima do Saf, sendo os Sistemas Agroflorestais, em geral, componentes promissores no controle da perda por lixiviação do Nitrogênio, tendo como principal agente para tal tarefa a associação entre as raízes das culturas de cultivo e das espécies florestais, realizando então a ciclagem deste desde a superfície do solo até as camadas mais profundas (SOUZA et al., 2019; ISMINIO, 2012), quantificando-se neste, na MIC, as maiores taxas de $\mathrm{OD}$, seguido pela $\mathrm{Vr}$ e, após, pela $\mathrm{Cp}$; assim como, em ambas as microbacias, maiores razões COD/NOD no Saf em relação a Tt. Associado a isto, temos na Tt um sistema com quantidade e diversidade de espécies limitada, consequentemente, com um menor número e disposição de raízes próximas a superfície do solo, que também atuam no retorno de nutrientes para a biomassa acima do solo (NEU, 2005; REGO et al., 2017), incompatíveis aos demais sistemas. O fato de, na MISJ, os valores de COD e NOD terem sido na Tt superiores aos da $\mathrm{Cp}$, ocorrendo o inverso na MIC, retoma a hipótese da função de capacidade de manutenção de umidade e matéria orgânica por este tipo de manejo anteriormente citada. 
Tabela 2: Médias gerais dos parâmetros analisados por tratamento e microbacia de estudo.

\begin{tabular}{|c|c|c|c|c|c|c|}
\hline $\begin{array}{l}\text { MIC } \\
\text { Parâmetros }\end{array}$ & Unidade & Ppt & $\begin{array}{l}\text { Lixiviado da serr } \\
\operatorname{Vr}\end{array}$ & $\begin{array}{l}\text { Iheira } \\
\mathrm{Cp}\end{array}$ & $\mathrm{Tt}$ & Saf \\
\hline$T$ & ${ }^{\circ} \mathrm{C}$ & $*$ & $22,66 \pm 2,10 \mathrm{Aa}$ & $23,82 \pm 3,67 \mathrm{Aa}$ & $22,90 \pm 2,22 \mathrm{Aa}$ & $22,18 \pm 1,80 \mathrm{Aa}$ \\
\hline $\mathrm{pH}$ & - & $*$ & $4,21 \pm 1,53 \mathrm{Bb}$ & $4,67 \pm 1,80 \mathrm{Ba}$ & $4,92 \pm 1,30 \mathrm{Ba}$ & $4,18 \pm 1,41 \mathrm{Bab}$ \\
\hline SALS & $\mathrm{mm}$ & $*$ & $0,68 \pm 0,34 \mathrm{Aa}$ & $0,30 \pm 0,04 \mathrm{Ab}$ & $0,40 \pm 0,32 \mathrm{Ab}$ & $0,46 \pm 0,27 A b$ \\
\hline CE & $\mathrm{mS}$ & $*$ & $1,53 \pm 4,07 \mathrm{Aa}$ & $1,82 \pm 4,15 \mathrm{Aa}$ & $1,04 \pm 3,72 \mathrm{Aa}$ & $0,92 \pm 1,55 \mathrm{Aa}$ \\
\hline$\% O D$ & $\%$ & $*$ & $68,11 \pm 31,79 \mathrm{Aa}$ & $60,84 \pm 28,81 \mathrm{Aa}$ & $59,95 \pm 27,84 \mathrm{Aa}$ & $69,65 \pm 23,21 \mathrm{Aa}$ \\
\hline COD & $\mathrm{mg} / \mathrm{L}$ & $16,75 \pm 24,31 \mathrm{Aab}$ & $22,93 \pm 12,37 \mathrm{Aa}$ & $22,73 \pm 14,87 \mathrm{Aab}$ & $16,79 \pm 7,40 \mathrm{Aab}$ & $10,35 \pm 8,11 \mathrm{Ab}$ \\
\hline CID & $\mathrm{mg} / \mathrm{L}$ & $1,81 \pm 1,70 \mathrm{Ab}$ & $1,24 \pm 1,15 \mathrm{Aa}$ & $0,94 \pm 1,35 \mathrm{Aa}$ & $1,16 \pm 0,95 \mathrm{Aa}$ & $0,43 \pm 0,27 \mathrm{Aa}$ \\
\hline NOD & $\mathrm{mg} / \mathrm{L}$ & $0,81 \pm 0,51 \mathrm{Aa}$ & $3,17 \pm 6,24 \mathrm{Ab}$ & $8,61 \pm 21,53 \mathrm{Ab}$ & $2,03 \pm 0,98 \mathrm{Ab}$ & $1,50 \pm 1,28 \mathrm{Ab}$ \\
\hline COD/NOD & & $17,52 \pm 21,25 \mathrm{Aa}$ & $13,30 \pm 5,41 \mathrm{Aa}$ & $9,10 \pm 4,93 \mathrm{Aa}$ & $9,07 \pm 4,93 \mathrm{Aa}$ & $10,59 \pm 12,47 \mathrm{Aa}$ \\
\hline $\mathrm{NH}_{4}^{+}$ & $\mathrm{mg} / \mathrm{L}$ & $0,34 \mathrm{Aa}$ & $1,09 \pm 1,48 \mathrm{Aa}$ & $0,59 \pm 0,63 \mathrm{Aa}$ & $0,56 \pm 0,61 \mathrm{Aa}$ & $0,27 \pm 0,25 \mathrm{Aa}$ \\
\hline $\mathrm{NO}_{3}^{-}$ & $\mathrm{mg} / \mathrm{L}$ & $1,03 \pm 1,40 \mathrm{Aa}$ & $2,86 \pm 3,73 \mathrm{Aa}$ & $1,25 \pm 1,59 \mathrm{Aa}$ & $5,23 \pm 8,99 \mathrm{Aa}$ & $0,32 \pm 0,30 \mathrm{Aa}$ \\
\hline MISJ & Innidade & Pnt & Lixiviado da serr & Iheira & & \\
\hline Parâmetros & Unidade & $P p \tau$ & $\mathrm{Vr}$ & $\mathrm{Cp}$ & $\mathrm{Tt}$ & Saf \\
\hline$T$ & ${ }^{\circ} \mathrm{C}$ & $*$ & $22,74 \pm 1,52 \mathrm{Aa}$ & $22,45 \pm 1,02 \mathrm{Aa}$ & $22,39 \pm 1,40 \mathrm{Aa}$ & $22,66 \pm 1,71 \mathrm{Aa}$ \\
\hline $\mathrm{pH}$ & - & $*$ & $4,30 \pm 1,17 \mathrm{Ab}$ & $5,20 \pm 0,66 \mathrm{Aa}$ & $5,14 \pm 0,98 \mathrm{Aa}$ & $5,74 \pm 0,46$ Aab \\
\hline SALS & $\mathrm{mm}$ & $*$ & $0,66 \pm 0,29 A a$ & $0,48 \pm 0,28 \mathrm{Ab}$ & $0,43 \pm 0,24 \mathrm{Ab}$ & $0,23 \pm 0,23 A b$ \\
\hline CE & $\mathrm{mS}$ & $*$ & $0,80 \pm 1,33 \mathrm{Bа}$ & $0,12 \pm 0,14 \mathrm{Ba}$ & $0,54 \pm 1,92 \mathrm{Ba}$ & $0,09 \pm 0,14 \mathrm{Ba}$ \\
\hline$\% O D$ & $\%$ & $*$ & $62,52 \pm 31,19 \mathrm{Aa}$ & $59,23 \pm 19,47 \mathrm{Aa}$ & $59,84 \pm 18,35 \mathrm{Aa}$ & $57,80 \pm 3,35 \mathrm{Aa}$ \\
\hline COD & $\mathrm{mg} / \mathrm{L}$ & $8,45 \pm 6,84$ Aab & $25,43 \pm 20,92 \mathrm{Aa}$ & $18,22 \pm 11,10 \mathrm{Aab}$ & $22,49 \pm 31,58 \mathrm{Aab}$ & $15,06 \pm 12,54 \mathrm{Ab}$ \\
\hline CID & $\mathrm{mg} / \mathrm{L}$ & $3,74 \pm 4,28 \mathrm{Ab}$ & $0,53 \pm 0,36 \mathrm{Aa}$ & $1,26 \pm 1,93 \mathrm{Aa}$ & $1,14 \pm 1,59 \mathrm{Aa}$ & $1,46 \pm 2,01 \mathrm{Aa}$ \\
\hline NOD & $\mathrm{mg} / \mathrm{L}$ & $1,15 \pm 1,47 \mathrm{Aa}$ & $13,45 \pm 30,72 A b$ & $3,79 \pm 4,53 \mathrm{Ab}$ & $4,88 \pm 6,97 \mathrm{Ab}$ & $2,70 \pm 2,90 \mathrm{Ab}$ \\
\hline COD/NOD & - & $9,80 \pm 6,64 \mathrm{Ba}$ & $7,39 \pm 6,51 \mathrm{Ba}$ & $7,24 \pm 3,2 \mathrm{Ba}$ & $8,20 \pm 8,81 \mathrm{Ba}$ & $9,07 \pm 5,45 \mathrm{Ba}$ \\
\hline $\mathrm{NH}_{4}^{+}$ & $\mathrm{mg} / \mathrm{L}$ & $0,08 \pm 0,01 \mathrm{Aa}$ & $0,42 \pm 0,43 \mathrm{Aa}$ & $0,72 \pm 0,87 \mathrm{Aa}$ & $0,41 \pm 0,44 \mathrm{Aa}$ & $0,61 \pm 0,88 \mathrm{Aa}$ \\
\hline $\mathrm{NO}_{3}^{-}$ & $\mathrm{mg} / \mathrm{L}$ & 0,41Aa & $0,59 \pm 0,47 \mathrm{Aa}$ & $4,75 \pm 5,70 \mathrm{Aa}$ & $4,32 \pm 8,33 \mathrm{Aa}$ & $9,34 \pm 19,69 \mathrm{Aa}$ \\
\hline
\end{tabular}

Médias, por parâmetro, que não compartilham a mesma letra (maiúsculas: microbacia, minúsculas: tratamentos) são significativamente diferentes pelo teste de Tukey a 5\%. ${ }^{*}=$ sem resultados. - = resultado adimensional.

Retornando a Figura 5, nota-se que dentre os tratamentos verificados no lixiviado da serrapilheira, para o COD, têm-se o Saf como aquele com as menores variações e resultados inferiores, acima apenas do obtido na precipitação, valendo ressaltar que este comportamento foi mais perceptível na MIC.

Tabela 3: Matriz de correlação de Spearman entre os parâmetros analisados nas duas microbacias.

\begin{tabular}{|c|c|c|c|c|c|c|c|c|c|c|}
\hline & $\mathrm{T}$ & $\mathrm{pH}$ & SALS & $\mathrm{CE}$ & $\% O D$ & COD & CID & NOD & $\mathrm{COD} / \mathrm{NOD}$ & $\mathrm{NH}_{4}^{+}$ \\
\hline \multirow[t]{2}{*}{$\mathrm{pH}$} & $0,155^{*}$ & & & & & & & & & \\
\hline & 0,018 & & & & & & & & & \\
\hline \multirow[t]{2}{*}{ SALS } & $-0,080$ & $-0,152 *$ & & & & & & & & \\
\hline & 0,266 & 0,033 & & & & & & & & \\
\hline \multirow[t]{2}{*}{ CE } & $-0,059$ & $-0,607 * *$ & $-0,295^{* *}$ & & & & & & & \\
\hline & 0,423 & 0,000 & 0,000 & & & & & & & \\
\hline \multirow[t]{2}{*}{$\% O D$} & $-0,604$ & $-0,074$ & $-0,280 *$ & 0,078 & & & & & & \\
\hline & 0,437 & 0,370 & 0,020 & 0,356 & & & & & & \\
\hline \multirow[t]{2}{*}{ COD } & 0,033 & $-0,160$ & $-0,059$ & 0,177 & $-0,147$ & & & & & \\
\hline & 0,800 & 0,215 & 0,485 & 0,201 & 0,384 & & & & & \\
\hline \multirow[t]{2}{*}{ CID } & 0,142 & 0,143 & $-0,092$ & 0,040 & $-0,149$ & 0,089 & & & & \\
\hline & 0,095 & 0,091 & 0,289 & 0,682 & 0,144 & 0,794 & & & & \\
\hline \multirow[t]{2}{*}{ NOD } & $-0,077$ & 0,203 & $-0,147$ & $-0,021$ & 0,043 & $0,433^{* *}$ & $0,756 * *$ & & & \\
\hline & 0,573 & 0,133 & 0,079 & 0,888 & 0,818 & 0,000 & 0,007 & & & \\
\hline \multirow[t]{2}{*}{ COD/NOD } & 0,174 & $-0,275^{*}$ & $0,272 * *$ & 0,017 & 0,219 & $0,218 * *$ & $-0,137$ & $-0,248 * *$ & & \\
\hline & 0,200 & 0,041 & 0,001 & 0,907 & 0,236 & 0,001 & 0,689 & 0,001 & & \\
\hline \multirow[t]{2}{*}{$\mathrm{NH}_{4}^{+}$} & 0,033 & 0,117 & $-0,195$ & 0,245 & $0,356^{*}$ & 0,691 & 0,091 & 0,703 & 0,527 & \\
\hline & 0,787 & 0,296 & 0,073 & 0,057 & 0,015 & 0,309 & 0,383 & 0,297 & 0,473 & \\
\hline \multirow[t]{2}{*}{$\mathrm{NO}_{3}^{-}$} & $-0,055$ & $-0,020$ & $-0,193$ & $0,272 *$ & $-0,023$ & $-0,292$ & $-0,044$ & $-0,231$ & $-0,300$ & $0,245^{*}$ \\
\hline & 0,621 & 0,855 & 0,077 & 0,037 & 0,885 & 0,525 & 0,680 & 0,619 & 0,514 & 0,022 \\
\hline
\end{tabular}

Valores: Coeficiente de correlação de Pearson ( $\rho$, acima) e P-valor (abaixo). ${ }^{*}=$ correlação significativa a nível de 0,05 . **=correlação significativa a nível de 0,01 .

Deve-se destacar que o posicionamento da precipitação, no que diz respeito a razão COD/NOD, acima do lixiviado da serrapilheira de ambas as microbacias (Tabela 2) pode estar relacionado às baixas concentrações de $\operatorname{NOD}(0,81 \pm 0,51 \mathrm{mg} / \mathrm{L}$ na MIC e 1,15 $\pm 1,47 \mathrm{mg} / \mathrm{L}$ na MISJ), cuja origem está mais atrelada a 
biomassa sobre o solo e processos microbiológicos, em detrimento de teores de COD mais elevados $(16,75 \pm 24,31 \mathrm{mg} / \mathrm{L}$ e $8,45 \pm 6,84 \mathrm{mg} / \mathrm{L})$.

De forma geral, o aumento simultâneo nas concentrações de COD e NOD, de acordo com as Figuras 5 e 6, ocorrido na MISJ durante os meses de menor precipitação atmosférica (de novembro a dezembro de 2014 , com mensurações de 7,4 mm e 21,8 mm, respectivamente, conforme a Figura 3) pode ser justificado pelo resultado da análise estatística, onde foi obtida correlação significativa $(p<0,01)$ e positiva entre ambos $(\sigma=0,433)$, como pode ser visualizado na Tabela 3 e na Figura 7.

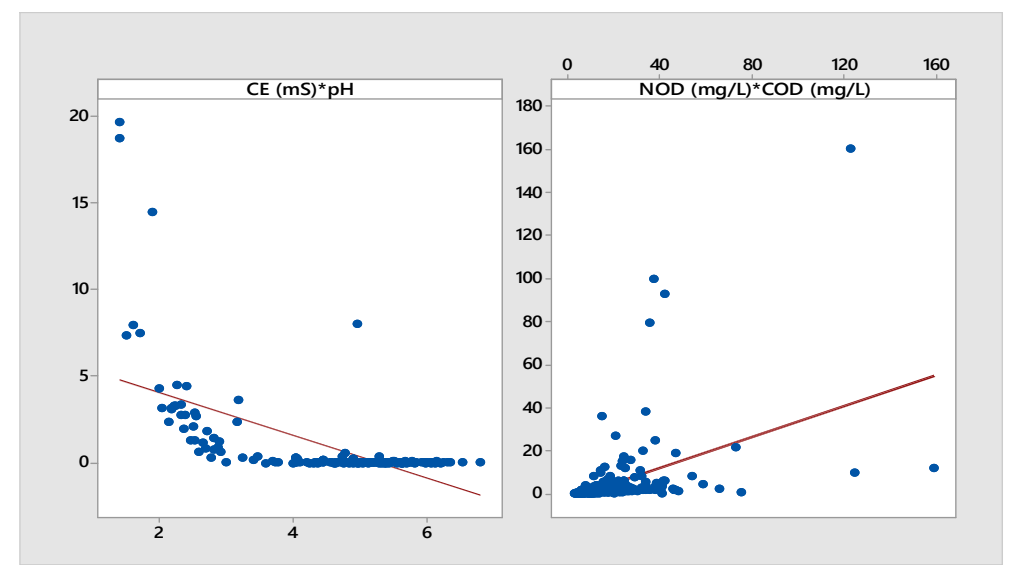

Figura 7: Correlação entre os parâmetros pH e condutividade (a esquerda, $\sigma=-0,607)$; NOD e COD (a direita, $\sigma=0,433$ ).

\section{Correlação entre variáveis: uma discussão geral acerca dos atributos implicados pelo material vegetal depositado sob o solo}

Neste estudo, como visto, áreas de vegetação intensa (vegetação ripária e capoeira) tiveram maiores volumes de água coletados, ricos em NOD e COD, entretanto, os nutrientes geralmente são escassos e com grande capacidade de perda em sistemas onde a produção agrícola é intensa, devido a perdas por processos de lixiviação no manejo de solo (áreas de trituração).

A estrutura da vegetação altera o fluxo de nutrientes na água de superfície após a entrada destes compostos via precipitação e atmosfera (SILVEIRA et al., 2011). Esta extensão de perda, principalmente de NOD, cresce com o aumento de precipitação e irrigação, com grande entrada de nitrogênio em solos mais arenosos (KESSEL et al., 2009). Geralmente, são substâncias de COD hidrofílicas e menos aromáticas (ANDREASSON et al., 2009).

Ao fato de que as concentrações de nutrientes lixiviados das folhas dependerão das espécies destas, do tipo de solo e da população microbiana, foi visto neste trabalho a influência somente das folhas coletadas nas calhas onde os compostos orgânicos de carbono e nitrogênio se destacaram no mix de folhas de várias espécies, também observado em vegetação secundária, estando de acordo com estudo de Silveira et al. (2011), que também encontraram as maiores proporções destes compostos em amostras com maior dimensão de folhas misturadas. Segundo estes autores, a liberação de carbono como COD é maior sem a interferência do solo e este componente consiste basicamente de substâncias húmicas e ácidos hidrofílicos; eles afirmam, ainda, que são as folhas e sua interação com o solo a maior rota para transformação de húmus em solos minerais. A concentração de nitrogênio na sua forma orgânica também dependerá do mix de folhas 
e principalmente do pH (Tabela 2) destacadas nas áreas de vegetação ripária e capoeiras, em que a razão COD/NOD são menores.

Podemos observar que no período chuvoso as menores concentrações de nutrientes se concentram em áreas ricas de vegetação (Figuras 5 e 6), principalmente na microbacia do Cumaru, e as maiores concentrações no período seco em áreas de trituração em ambas as microbacias. Como já dito em discussões anteriores, aqui pode-se ter o efeito da diluição em quantidades maiores de água no período chuvoso.

Como o período seco se destaca com pH maiores e, por consequência, maiores valores de NOD (Figuras 4 e 6), levanta-se a questão da pouca precipitação ou irrigação levar ao acúmulo de material orgânico desfavorecendo processos de degradação de NOD. Kessel et al. (2009) enfatizam que a aplicação de fertilizantes e a multiplicidade de espécies de folhas de grande porte, neste caso, existentes em SAFs e vegetações ripárias, favorecem a presença de NOD como entrada de nitrogênio no solo.

As concentrações de nitrogênio inorgânico $\left(\mathrm{NO}_{3}{ }^{-}\right.$e $\mathrm{NH}_{4}{ }^{+}$, ambos na Figura 6) se destacaram no $\mathrm{Tr}$, principalmente em áreas de SAFs e manejo com trituração, onde observa-se pH entre 5 e 6 . Estas formas de nitrogênio se distinguem em áreas manejadas no solo com determinadas características, e suas diferenças na comunidade microbiana dependem das espécies de plantas presentes que governam a mineralização de nitrogênio em formas inorgânicas, como também destacados em trabalhos de Silveira et al. (2011) e Kessel et al. (2009). Parece que nestas áreas o processo de mineralização de nitrogênio para a produção de nitrato (altamente solúvel em água), bem como conversão do amônio para nitrato, ocorre rapidamente. No Tr2 a reintrodução da água da chuva poderá ser o começo da nitrificação do NOD acumulado no período seco, que com a rápida mineralização e nitrificação provocam o aumento de concentração de nitrato e amônio na solução do lixiviado da serrapilheira. Tietema et al. (1992) mostraram a correlação positiva linear entre teor de umidade, $\mathrm{pH}$ e o processo de nitrificação na presença de solo, além da mudança rápida na velocidade de nitrificação com mudanças de $\mathrm{pH}$. A ausência de solo, pelo fato do lixiviado da serrapilheira ser recolhido acima deste, afeta os processos biogeoquímicos destes nutrientes, uma vez que as flutuações de nitrogênio inorgânico são maiores em determinados tipos de população microbiana e teores de umidade no solo. A forma orgânica de nitrogênio (NOD) é mais evidente nas folhas sem a presença de solo do que as formas inorgânicas do mesmo (SILVEIRA et al., 2011).

A relação de acúmulo de nutrientes vem sendo ressaltada por alguns autores (CATÂNIO et al., 2002) também em capoeiras, onde a composição e a concentração de nutrientes na serrapilheira influenciam na matéria orgânica disponível e, por consequência, na diversidade de mesofauna do solo e em seus processos bioquímicos. Não houve diferenças entre os tipos de vegetação estudados com relação aos nutrientes NOD, $\mathrm{COD}, \mathrm{NH}_{4}{ }^{+}$e $\mathrm{NO}_{3}{ }^{-}$, visto que a concentração de folhas, raízes e galhos em todos os sistemas foram acumulados mensalmente nas calhas, se diferenciando apenas pelo tipo de material de biomassa acumulada em cada área, entretanto, o mix de material se diferenciou no $\mathrm{pH}$ dos extratos.

Ainda no que se refere ao amônio, nota-se que este (conforme a Tabela 3) aparenta ter outros fatores que influenciam sua presença no meio em questão, onde não há correlação significativa $(p>0,05)$ entre todos os demais parâmetros verificados, a exceção da \%OD e do $\mathrm{NO}_{3}{ }^{-}$, sugerindo-se que a sua presença esteja mais 
dependente da composição microbiológica do meio no processo de nitrificação e do manejo das plantas e do solo, como também observado por Silveira et al. (2011). A fraca correlação positiva $(\sigma=0,356)$, porém a níveis significativos $(p<0,05)$, entre este cátion nitrogenado e a \%OD, que está atrelada aos processos metabólicos aeróbios, constata a hipótese anteriormente citada.

O interessante neste estudo, é que todos os sistemas pelo acúmulo de folhas, galhos e raízes se mostraram ricos em carbono, nitrogênio e nutrientes inorgânicos. A sua perda irá ocorrer no solo, pela presença de outros fatores, abióticos ou bióticos. Nas duas microbacias, estes sistemas proporcionaram concentrações em destaque de COD e nitrato, devido ao seu acúmulo de galhos e folhas em decomposição para preparo de área. Kato et al. (2008), relatam melhores crescimentos de plantas (plantios de maracujá) em áreas preparadas com o sistema de corte e trituração de capoeiras (pousio de 2 anos), uma vez que em áreas de derruba e queima foram obtidos menores desempenhos de crescimento. A importância das folhas e raízes expostas no solo é evidenciada pela ciclagem de nutrientes no mesmo, podendo chegar a profundidades significantes para absorção de nutrientes às plantas evitando os processos de lixiviação e perdas por erosão do solo.

\section{Análise temporal entre temperatura e $\mathrm{NO}_{3}{ }^{-}$}

Aos resultados do teste de Tukey a $5 \%$, conforme a Tabela 2, entre os tratamentos para as variáveis Temperatura, \%OD, $\mathrm{NH}_{4}{ }^{+}$e $\mathrm{NO}_{3}{ }^{-}$em associação com os testes de variância, nota-se ainda a presença de resultados sem diferença significativa $(p>0,05)$. Ao ser a análise adaptada mediante a inclusão da mensuração do fator estação chuvosa, foi constatada a mudança deste comportamento $($ com $p<0,01)$ nos dados de Temperatura e $\mathrm{NO}_{3}^{-}$.

Em relação a Temperatura, conforme a Figura 3, nota-se a drástica mudança no regime pluviométrico no decorrer dos meses, acontecimento ligado diretamente às interações climáticas existentes. Após a adaptação do teste mencionado anteriormente, foi demonstrada a distinção entre os períodos Tr2 e Es, em relação aos Ch e Tr1, assim como uma semelhança, a nível de significância entre os períodos Ch e Es. A análise descritiva deste parâmetro resultou no posicionamento das transições, em linha geral, nos limites inferior $\left(\operatorname{Tr} 1,21,58 \pm 0,55^{\circ} \mathrm{C}\right.$ na MIC e $21,95 \pm 0,53^{\circ} \mathrm{C}$ na MISJ) e superior (Tr2, a exceção da MISJ, com $25,39 \pm 3,27^{\circ} \mathrm{C}$ na MIC e $22,76 \pm 1,12{ }^{\circ} \mathrm{C}$ na MISJ), no que diz respeito aos dados obtidos, ressaltando assim a representatividade destes em relação aos tidos, em geral, como principais períodos, sendo estes Ch $\left(22,22 \pm 1,78^{\circ} \mathrm{C}\right.$ e $\left.22,48 \pm 1,60^{\circ} \mathrm{C}\right)$ e $\operatorname{Es}\left(23,13 \pm 0,45^{\circ} \mathrm{C}\right.$ e $\left.23,55 \pm 0,64^{\circ} \mathrm{C}\right)$.

Para $\mathrm{O} \mathrm{NO}_{3}^{-}$foi observado o mesmo comportamento, quantificando-se igual distinção da $\operatorname{Tr} 1$

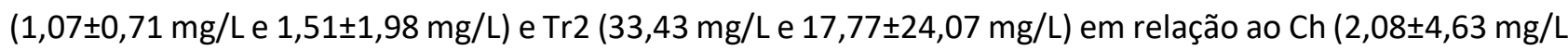
e $2,82 \pm 5,47 \mathrm{mg} / \mathrm{L})$ e a $E s(5,60 \pm 7,01 \mathrm{mg} / \mathrm{L}$ e $4,17 \pm 5,54 \mathrm{mg} / \mathrm{L})$. A esta espécie química, caracterizada por sua fácil perda por lixiviação, tal relação explica-se devido ao fato de que a maior incidência dos processos de percolação (acarretado pela maior precipitação dos períodos chuvoso e transição seco-chuvoso) associa-se a sua baixa interação com a matéria orgânica e os coloides do solo, podendo gerar a contaminação de mananciais ou lençóis freáticos (MENDES, 2016), além de afetar também as concentrações de nitrogênio 
mineral do solo (FIGUEIREDO, 2016).

\section{Correlação entre COD/NOD, SALS, pH e condutividade}

De acordo com a Tabela 2, foi evidenciado um caráter mais ácido na MIC, com valores de pH mais baixos no lixiviado da serrapilheira dos tratamentos Saf e Vr (com mínimas observadas em março de 2014, mês antecessor ao de maior intensidade de chuvas, observados os valores de $3,07 \pm 1,82$ e $3,67 \pm 1,90$, respectivamente), sendo estes tratamentos significativamente semelhantes e distintos dos demais, segundo o teste de Tukey a 5\%, cujos resultados podem estar relacionados a maior presença de ácidos orgânicos, alavancado pela diversidade de folhas nestas áreas e pela presença de frações que são facilmente degradáveis e móveis (devido ao contato com água da chuva), sendo porções de compostos orgânicos desorvidas das folhas das plantas mais rapidamente, onde a decomposição por micro-organismos será facilmente iniciada. De mesmo modo, foram observados valores de condutividade mais elevados na MIC, verificando-se distinção significativa apenas entre as microbacias $(p<0,05)$, não havendo, portanto, distinção entre os tratamentos estudados ( $p>0,05)$. Esta relação é constatada pela correlação negativa e moderada obtida pela associação destas variáveis $(\sigma=-0,607, p=0,000)$, bem como pela correlação entre $p H$ e a razão COD/NOD $(\sigma=-0,275, p=0,041)$, ambas vistas na Tabela 3 e na Figura 7.

No que se refere aos tratamentos onde foi observada maior acidez (Saf e Vr da MIC) nota-se ainda, conforme o observado na Tabela 2, os maiores valores de SALS e COD/NOD obtidos no lixiviado da serrapilheira desta microbacia (acima de $0,45 \mathrm{~mm}$ e acima de 10 , respectivamente), onde neste estudo foi averiguada baixa correlação negativa $(\sigma=-0,152)$, porém significativa $(p<0,05)$, entre estes dois parâmetros (SALS e pH, contida na Tabela 3). Isto condiz com o afirmado anteriormente acerca do crescimento das taxas de carreamento de ácidos orgânicos com a intensificação das chuvas, acarretado pela maior diversidade presente nestes dois tratamentos (formados por diferentes espécies de plantas com distintas composições de clorofila, lignina, e processos metabólicos diferenciados), fato que reafirma a importância e potencialidade dos SAFs. Quanto a isto, vale ressaltar que na MIC o Saf é constituído por um consórcio entre açaizeiros (Euterpe olerácea Mart.), seringueiras (Hevea brasiliensis) e cupuaçuzeiros (Theobroma grandiflorum), mencionado anteriormente na Tabela 1, estruturado a mais de 10 anos e que apresenta espessa camada de serrapilheira que, segundo Menezes (2018), forma uma espécie de "cama" sobre o solo, contribuindo na incorporação de nutrientes.

\section{CONCLUSÕES}

Os períodos de transição (chuvoso-estiagem e estiagem-chuvoso), onde ocorre a mudança gradual ou abrupta das condições climatológicas, possuem potencial significativo em relação a disponibilidade de nutrientes.

No período de maior intensidade de chuvas acelera-se o processo de lixiviação da matéria orgânica (contendo ácidos orgânicos), resultando no aumento da acidez na superfície, onde foi constatado na MIC lixiviados mais ácidos, bem como na ampliação dos processos respiratórios, acarretando um maior consumo 
de oxigênio. Já no período de menor pluviosidade, têm-se que o aumento na deposição de material proveniente da parte aérea do ecossistema atua gerando uma elevação nos teores de COD e NOD, principalmente em sistemas naturais e mais diversificados. No que se refere a isto, os SAFs, dado a sua complexidade, atuam significativamente na ciclagem e aproveitamento dos nutrientes lixiviados sob o solo; enquanto que nos sistemas de corte e trituração a baixa pluralidade de espécies é positivamente compensada pelo manejo da área.

Observou-se acréscimo nos valores de CID nos lixiviados da serrapilheira conforme a redução de chuvas, pois com menor volume de água há maior concentração de compostos inorgânicos carbonatados, que antes estavam diluídos. As taxas de CID foram, porém, regularmente maiores na precipitação do que no lixiviado.

Houve, ainda, maior entrada de Nitrogênio nos sistemas pela matéria orgânica do que pela precipitação, posto que este pouco foi identificado na precipitação. Ademais, esteve em maior quantidade no lixiviado da serrapilheira, o que ocorreu principalmente com os compostos inorgânicos $\left(\mathrm{NH}_{4}^{+}\right.$e $\left.\mathrm{NO}_{3}{ }^{-}\right)$, por terem origem atrelada a processos microbiológicos no solo.

AGRADECIMENTOS: Ao projeto Agrohidro e aos laboratórios de Análises de Sistemas Sustentáveis (LASS), Meteorologia e Sensoriamento Remoto (LSR), ambos da Embrapa Amazônia Oriental.

\section{REFERÊNCIAS}

ANDREASSON, F.; BERGKVIST, B.; BAATH, E.. Bioavailability of DOC in leachates, soil matrix solution and soil water extracts from beech forest floors. Soil Biology and Biochemistry, v.41, n.8, p.1652-1658, 2009. DOI: Https://doi.org/10.1016/j.soilbio.2009.05.005

BARREIROS, J. L.. Efeito do manejo florestal sustentável sobre a deposição de serapilheira em uma floresta de terra firme na Amazônia brasileira. Dissertação (Mestrado em Ciência e Tecnologia para Recursos Amazônicos) Universidade Federal do Amazonas, Itacoatiara, 2019.

CARVALHO, H. C. S.; FERREIRA, J. L. S.; CALIL, F. N.; SILVANETO, C. M.. Estoque de nutrientes na serapilheira acumulada em quatro tipos de vegetação no Cerrado em Goiás, Brasil. Ecologia e Nutrição Florestal, Santa Maria, v.7, n.6, p.1-12, 2019. DOI:

http://dx.doi.org/10.5902/2316980X37296

CATÂNIO, J. H.; DAVIDSON, E. A.; NEPSTAD, D. C.; VERCHOT, L. V.; ACKERMAN, I. L.. Unexpected results of a pilot throughfall exclusion experiment on soil emissions of $\mathrm{CO}_{2}$, $\mathrm{CH}_{4}, \mathrm{~N}_{2} \mathrm{O}$, and $\mathrm{NO}$ in eastern Amazônia. Biology and Fertillity of Soils, v.36, n.1, p.102-108, 2002. DOI: https://doi.org/10.1007/s00374-002-0517-x

CRUZ, E. K. S.; OLIVEIRA JÚNIOR, R. C.; BELDINI, T. P.; SILVA, A. D.. Fluxo de nutrientes em precipitação direta e interna na Floresta Nacional do Tapajós, Belterra, Pará. Revista Ibero Americana de Ciências Ambientais, Aracaju, v.9, n.4, p.7382, 2018. DOI: http://doi.org/10.6008/CBPC2179$\underline{6858.2018 .004 .0006}$

DARWICH, A. J.; APRILE, F. M.; ROBERTSON, B. A.; ALVES, L. F.. Limnologia do Lago Tupé: dinâmica espaço-temporal do oxigênio dissolvido. In: SANTOS-SILVA, E. N.; APRILE, F. M.;
SCUDELLER, V. V.; MELO, S.. Bio Tupé: meio físico, diversidade biológica e sociocultural do Baixo Rio Negro, Amazônia Central. Manaus: INPA, 2005. p.35-67.

DICKOW, K. M. C.; MARQUES, R.; PINTO, C. B.. Lixiviação de nutrientes da serapilheira recém-depositada em sucessão ecológica na floresta Atlântica, litoral do Paraná. Floresta, Curitiba, v.39, n.1, p.145-156, 2009. DOI: http://dx.doi.org/10.5380/rf.v39i1.13734

ENCINAS, O. C.. Dinâmica da água e nutrientes na solução do solo em um dendezal (Elaeis guineensis Jacq.) na Amazônia central. Tese (Doutorado em Agronomia Tropical) - Universidade Federal do Amazonas, Manaus, 2016.

FIGUEIREDO, A. E. S.. Dinâmica de nitrogênio em solos de florestas secundárias sob diferentes históricos de uso nos municípios de Santarém e Belterra, Amazônia Oriental. Dissertação (Mestrado em Ciências de Florestas Tropicais) Instituto Nacional de Pesquisas da Amazônia, Manaus, 2016.

ISMINIO, P. L.. Nitrato e amônio na solução do solo sob diversos sistemas agrícolas. Dissertação (Mestrado em Ciências) - Universidade Federal de Viçosa, Viçosa, 2012.

KATO, O. R.; CARVALHO, C. J. R.; FIGUEIREDO, R. O.; VASCONCELOS, S.; SÁ, T. D. A.; COSTA, J. R.; SCHWARZBACH, J.; OLIVEIRA, J. S. R.. Alternativas ao uso do fogo no preparo de área para o plantio, com base no manejo da capoeira na Amazônia. In: SEMINÁRIO O FOGO NO MEIO RURAL E A PROTEÇÃO DOS SÍTIOS DO PATRIMÔNIO MUNDIAL NATURAL DO BRASIL: ALTERNATIVAS, IMPLICAÇÕES SOCIOECONÔMICAS, PRESERVAÇÃO DA BIODIVERSIDADE E MUDANÇAS CLIMÁTICAS, 2. Anais. Brasília: Unesco, 2008. 
KESSEL, C.; CLOUGH, T.; VAN GROENIGEN, J. W.. Dissolved Organic Nitrogen: An Overlooked Pathway of Nitrogen Loss from Agricultural Systems?. Journal of Environmental Quality, v.38, n.2, p.393-401, 2009. DOI: http://doi.org/10.2134/jeq2008.0277

LIKENS, G. E.; HEDIN, L. O.; BUTLER, T. J.. Some long term precipitation chemistry patterns of the Hubbard Brook Experimental Forest: extremes and averages. Verh. Internat. Verein. Limol, v.24, n.1, p.128-135, 1990. DOI: https://doi.org/10.1080/03680770.1989.11898704

LIMA, A. M. M.; CRUZ, F. M.; CAVALCANTE, L. M.; CHAVES, L. M. L.; IMBIRIBA JUNIOR, M.; SANTOS, V. J. C.. A gestão da oferta hídrica no Estado do Pará e seus aspectos condicionantes. Revista Brasileira de Recursos Hídricos, Porto Alegre, v.15, n.3, p.69-83, 2010. DOI: http://dx.doi.org/10.21168/rbrh.v15n3.p69-83

MAESTRI, M. P.; AQUINO, M. G. C.; CARNEIRO, F. S.. Efeito da manipulação de nutrientes sobre as concentrações de carbono e nitrogênio da serapilheira em vegetação secundária, Amazônia Oriental. Brazilian Journal of Development, Curitiba, v.5, n.12, p.29646-29660, 2019. DOI: https://doi.org/10.34117/bjdv5n12-110

MENDES, W. C.. Perdas de nitrato e potássio em solos arenoso e argiloso e no cultivo do feijoeiro sob lâminas crescentes de irrigação. Tese (Doutorado em Agronomia) Universidade Federal de Goiás, Goiânia, 2016.

MENEZES, L. G. C.. Qualidade das águas superficiais e subterrâneas das microbacias do Cumaru e São João, nordeste paraense. Tese (Doutorado em Ciências Ambientais) - Universidade Federal do Pará, Belém, 2018.

MIRANDA, F. S. M.; AVELAR, A. S.. Dinâmica de carbono orgânico dissolvido em ecossistemas florestais: uma revisão sobre a lixiviação pela chuva. Revista Brasileira de Geografia Física, Recife, v.11, n.7. p.2351-2374, 2018. DOI: https://doi.org/10.26848/rbgf.v11.07.p2351-2374

NEILL, C.; DEEGAN, L. A.; THOMAS, S. M.; CERRI, C. C. Deforestation for pasture alters nitrogen and phosphorus in small amazonian streams. Ecological Aplications, v.11, n.6, p.1817-1828, 2001. DOI: https://doi.org/10.1890/10510761(2001)011[1817:DFPANA]2.0.CO;2

NEU, V.. Influência da cobertura vegetal na ciclagem de nutrientes via solução do solo na região de Manaus, AM. Dissertação (Mestrado em Ecologia de Agroecossistemas) Universidade de São Paulo, São Paulo, 2005.

OLIVEIRA, T. P.; ENSINAS, S. C.; BARBOSA, G. F.; NANZER, M. C.; BARRETA, P. G. V.. Atributos químicos de um neossolo quartzarênico de cerrado sob diferentes sistemas de uso e manejo. Revista de Agricultura Neotropical, Cassilândia, v.4, n.1, p.72-78, 2017. DOI:

https://doi.org/10.32404/rean.v4i5.2182

REGO, A. K. C.; KATO, O. R.. Agricultura de corte e queima e alternativas agroecológicas na Amazônia. Novos Cadernos NAEA, Belém, v.20, n.3, p.203-224, 2017. DOI: http://dx.doi.org/10.5801/ncn.v20i3.3482
ROSA, M. B. S.. Dinâmica de carbono em pequenas bacias de drenagem sob uso de agricultura familiar na Amazônia Oriental. Dissertação (Mestrado em Ciências Ambientais) Universidade Federal do Pará, Belém, 2007.

SHIMIZU, M. K.; KATO, O. R.; FIGUEIREDO, R. O.; VASCONCELOS, S. S.; SÁ, T. D. A.; BORGES, A. C. M. R.. Agriculture without burning: Restoration of altered areas with chop-and-mulch sequential agroforestry systems in the Amazon region. Global Advanced Research Journal of Agricultural Science, v.3, n.12, p.415-422, 2014.

SILVA, B. N. R.; RODRIGUES, T. E.; GERHARD, P.. Solos das mesobacias hidrográficas dos igarapés São João e Cumaru, municípios de Marapanim e igarapé Açu. In: CONGRESSO BRASILEIRO DE CIÊNCIA DO SOLO, 32. Anais. Fortaleza: SBCS, 2009.

SILVA, M. G. M.; FIGUEIREDO, R. O.; ROSA, M. B. S.; COSTA, F. F.. Variação espaço-temporal de carbono orgânico dissolvido em três pequenas bacias de drenagem na Amazônia Oriental. In: CONGRESSO DE ECOLOGIA DO BRASIL, 8. Anais. Caxambu: SBE, 2007.

SILVEIRA, M. L.; REDDY, K. R.; COMERFORD, N. B.. Litter decomposition and soluble carbon, nitrogen, and phosphorus release in a forest ecosystem. Open Journal of Soil Science, v.1, n.3, p.86-96, 2011. DOI: http://doi.org/10.4236/ojss.2011.13012

SOMMER, R.; VLEK, P. L. G.; SÁ, T. D. A.; VIELHAUER, K.; COELHO, R. F. R.; FÖLSTER, H.. Nutrient balance of shifting cultivation by burning or mulching in the Eastern Amazon evidence for subsoil nutrient accumulation. Nutrient Cycling in Agroecosystems, v.68, n.3, p.257-271, 2004. DOI: https://doi.org/10.1023/B:FRES.0000019470.93637.54

SOUSA, E. S.. Dinâmica do carbono dissolvido no Rio Acre: variações espaciais e sazonais. Dissertação (Mestrado em Ciências Ambientais) - Universidade Federal do Pará, Belém, 2007.

SOUZA, A. S.; KATO, O. R.; FREITAS, L. S.; GALVÃO, J. R. Propriedades e estoque de carbono e nitrogênio do solo na Amazônia Oriental: um estudo de caso sobre os sistemas de manejo. Revista Observatório de la Economía Latinoamericana, Belém, v.17, n.1, p.1-17, 2019.

TIETEMA, A.; BOER, W.; RIEMER, L.; VERSTRATEN, J. M.. Nitrate production in nitrogen-saturated acid forest soils: vertical distribution and characteristics. Soil Biology and Biochemistry, v.24, n.3, p.235-240, 1992. DOI: https://doi.org/10.1016/0038-0717(92)90224-L.

TROEH, F. R.; THOMPSON, L. M.. Solos e fertilidade do solo. Tradução de Durval Dourado Neto e Manuella Nóbrega Dourado. 6 ed. São Paulo: Andrei, 2007.

TUNDISI, J. G.; MATSUMURA-TUNDISI, T.. Limnologia. São Paulo: Oficina de Textos, 2008.

WICKEL, A. J.; GIESEN, N. V. D.; VIELHAUER, K.; SÁ, T.; DENICH, M.. Effects of fier-free land preparation on water and nutrient dynamics at a watershed level in a shifting cultivation environment in Eastern Amazônia. In: SCIENCE CONFERENCE. Anais. Amsterdam, 2001.

A CBPC - Companhia Brasileira de Produção Científica (CNPJ: 11.221.422/0001-03) detém os direitos materiais desta publicação. Os direitos referem-se à publicação do trabalho em qualquer parte do mundo, incluindo os direitos às renovações, expansões e disseminações da contribuição, bem como outros direitos subsidiários. Todos os trabalhos publicados eletronicamente poderão posteriormente ser publicados em coletâneas impressas sob coordenação da Sustenere Publishing, da Companhia Brasileira de Produção Científica e seus parceiros autorizados. Os (as) autores (as) preservam os direitos autorais, mas não têm permissão para a publicação da contribuição em outro meio, impresso ou digital, em português ou em tradução. 